\title{
Early Nutrition and Later Excess Adiposity during Childhood: A Narrative Review
}

\author{
Iris Iglesia Altaba a, b, c Elvira Larquéb, d María Dolores Mesab, e, \\ José Eliseo Blanco-Carnerog Carolina Gomez-Llorente ${ }^{\mathrm{e}, \mathrm{f}, \mathrm{h}}$ \\ Gerardo Rodríguez-Martínez ${ }^{\mathrm{a}, \mathrm{b}, \mathrm{c}, \mathrm{i}}$ Luis A. Moreno ${ }^{\mathrm{a}, \mathrm{c}, \mathrm{h}}$
}

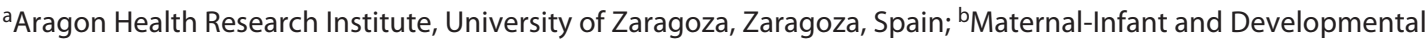
Health Network (SAMID), RETICS Carlos III Health Institute (ISCIII), Madrid, Spain; 'Growth, Exercise, Nutrition and Development (GENUD), Faculty of Health Sciences, University of Zaragoza, and Instituto Agroalimentario de Aragón

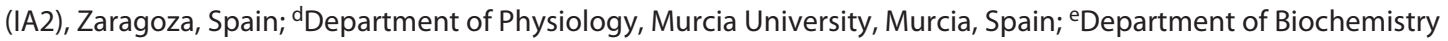
and Molecular Biology II, School of Pharmacy. Institute of Nutrition and Food Technology "José Mataix", Biomedical Research Center, University of Granada, Granada, Spain; fibs.GRANADA, Biosanitary Research Institute, Granada,

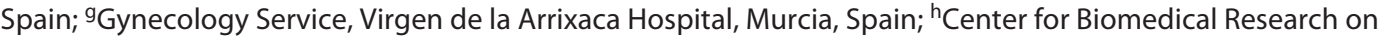
Physiopathology of Obesity and Nutrition (CIBERObn), Instituto de Salud Carlos III, Madrid, Spain; iDepartment of Pediatrics, Faculty of Medicine, University of Zaragoza, Zaragoza, Spain
\end{abstract}

\section{Keywords}

Programming · Epigenetics · Infant feeding · Microbiome · Adiposity

\begin{abstract}
Background: Studies on childhood obesity mainly focus on the genetic component and on the lifestyle that may be associated with the development of obesity. However, the study of perinatal factors in their programming effect toward future obesity in children or adults is somewhat more recent, and there are still mechanisms to be disentangled. Summary: In this narrative review, a comprehensive route based on the influence of some early factors in life in the contribution to later obesity development is presented. Maternal pre-pregnancy BMI and gestational weight gain have been pointed out as independent determinants of infant later adiposity. Lifestyle interventions could have an impact on
\end{abstract}

pregnant mothers through epigenetic mechanisms capable of redirecting the genetic expression of their children toward a future healthy weight and body composition and dietary-related microbiome modifications in mothers and newborns might also be related. After birth, infant feeding during the first months of life is directly associated with its body composition and nutritional status. From this point of view, all the expert committees in the world are committed to promote exclusive breastfeeding up to 6 months of age and to continue at least until the first year of life together with complementary feeding based on healthy dietary patterns such as Mediterranean Diet. Key Messages: To develop future effective programs to tackle early obesity, it is necessary not only by controlling lifestyle behaviors like infant feeding but also understanding the role of other mechanisms like the effect of perinatal factors such as maternal diet during pregnancy, epigenetics, or microbiome.

(c) 2021 S. Karger AG, Basel karger@karger.com

(C) 2021 S. Karger AG, Basel

www.karger.com/hrp

Karger ${ }^{\prime \prime}=$
Correspondence to:

Iris Iglesia Altaba, iglesia@ unizar.es 


\section{Introduction}

Obesity is a complex multifactorial condition [1]. Therefore, it is crucial to understand the role and the weight of each genetic and nongenetic related factors on its onset and development. When its onset occurs during childhood, represents a significant risk factor of obesity and obesityrelated complications in adulthood specific perinatal factors. The knowledge on the impact of the first 1,000 days of life for programming the development of future health is still quite recent [2] and new knowledge, about metabolic pathways and the role of epigenetic mechanisms and the gut microbiome, would be essential in this regard.

Probably the first exposure to evaluate in this sense is the effects of maternal obesity on fetal metabolic programming in humans. There are still some knowledge gaps or contradictory findings in this respect, so cohort studies evaluating differences among siblings according to maternal pre-pregnancy BMI are of major interest as well as studies considering the different associations between the offspring according to maternal and paternal BMI. In fact, the best example comes from the studies comparing siblings born from mothers with obesity, before and after gastrointestinal bypass surgery in which lower prevalence of macrosomia (1.8 vs. $14.8 \%$ ), and severe obesity at adolescence occurred in siblings born after maternal surgery (11 vs. $35 \%$ ) [3].

Adipose tissue is one of the most active metabolic and endocrine tissues that synthesizes and secretes a wide variety of molecules; so maternal obesity and/or its inadequate nutrition might modulate key genes expression or gut microbial composition, with potential health implications such as the offspring and development of the child obesity. Around this question, there is also a constantly rising body of evidence requiring attention.

After birth, of course, nutrition plays a determinant role in the development of obesity. During first months of life, scientists worldwide agreed with the beneficial effects of exclusive breastfeeding while still there are controversies in relation with its implication on its protective effect against obesity, as well as with the introduction of complementary foods.

Apart from nutrition, there is a number of other early life factors which seem to be crucial as part of the programming for later diseases such as obesity or cardiovascular disease. Growth belongs to these early life factors and the question, whether birth weight for instance, is a predictor of later overweight/obesity remains unclear.

To answer all these questions, this review focused on systematic reviews, original papers and scientific reports trying to fill and summarize all these gaps to identify early opportunities to tackle childhood obesity. The literature search was systematic at first, but reduced according to expert opinions and it focuses on Nutrition during pregnancy and child adiposity programming, New evidence on metabolic pathways, Postnatal determinants of excess adiposity and the influence of early nutrition on microbiota and later obesity risk.

\section{Nutrition during Pregnancy and Child Adiposity Programming}

Maternal pre-pregnancy BMI and gestational weight gain are both positively and independently associated with neonatal and infant adiposity [4]. In addition, in a recent meta-analysis with 162,129 mothers and their children from 37 pregnancy and birth cohort studies from Europe, North America, and Australia, it was shown that the proportions of childhood overweight/obesity prevalence attributable to maternal overweight, maternal obesity, and excessive gestational weight gain ranged from $10.2 \%$ to $21.6 \%$ [5]. Indeed, maternal BMI was stronger predictor of childhood obesity than paternal BMI [4] since the demethylations of the zygote during pregnancy delete some of the paternal epigenetic marks [6]. Nevertheless, mothers being the main caregivers in many cultures/countries are also an important factor to explain the higher association of maternal BMI than paternal BMI [7].

Diet and physical activity-based interventions during pregnancy may reduce gestational weight gain and lower the odds of caesarean section $[8,9]$. Pregnant women need to increase just about $10-15 \%$ of the energy in their diet, and not to eat by 2 while to think by 2 [10] to have an adequate gestational weight gain for a healthy pregnancy as recommended by the World Health Organization and be informed that it is even more important to start pregnancy with a BMI in the normal range (18.5$24.9 \mathrm{~kg} / \mathrm{m}^{2}$ ) [11].

When considering specific macronutrients, for instance, high-glycemic index diet during pregnancy is associated with a higher prevalence of large for gestational age and greater adiposity in the offspring at birth [12]. Consistently, increased odds of overweight/obesity in offspring at 5 and 6 years were found in large cohort studies in mothers with higher intakes of sugar during pregnancy [13]. However, intervention studies on maternal dietary glycemic index during pregnancy have achieved modest success in decreasing excessive gestational weight gain 
Table 1. Classification (protect vs. no effect) of studies showing the association between the adherence to Mediterranean diet during pregnancy and either maternal or fetal outcomes

\begin{tabular}{|c|c|c|}
\hline Variable & Protect & No effect \\
\hline $\begin{array}{l}\text { Birthweight, } \\
\text { adiposity }\end{array}$ & $\begin{array}{l}11 \text { (Timmermans et al. [19]; Chatzi et al. [21, 22]; Smith et al. [23]; Monteagudo et al. } \\
\text { [24]; Parlapani et al. [25]; Gómez-Roig et al. [26]; Assaf-Balut et al. [27]; } \\
\text { Martínez Galiano et al. [28]; Peraita-Costa et al. [29]; Fernández-Barres et al. [30]) }\end{array}$ & $\begin{array}{l}5 \text { (Saunders et al. [31]; Fernández-Barres } \\
\text { [32]; Castro-Rodriguez et al. [33]; } \\
\text { Tomaino et al. [34]; Peraita-Costa et al. [35]) }\end{array}$ \\
\hline $\begin{array}{l}\text { Gestational diabetes } \\
\text { and Preeclampsia }\end{array}$ & $\begin{array}{l}7 \text { (Assaf-Balut et al. [27, 36]; Parlapani et al. [25]; Al Wattar et al. [37]; } \\
\text { Olmedo-Requena el al. [38]; García de la Torre et al. [39]; Melero et al. [40]) }\end{array}$ & \\
\hline
\end{tabular}

[9], reduce infant adiposity measured as subscapular thickness and produce sustained improvement in maternal diet at 6 months postpartum [14], and reduced birth weight above 4,000 g but not child growth and adiposity at 3-5 years in the offspring in the Limit Trial [15]. Maternal fat and protein intakes were not consistently associated with infant BMI peak and childhood BMI from 18 months to 4 years old [16]. Higher maternal protein intake at the expense of carbohydrate or fat intake at 26- to 28-week gestation was associated with lower abdominal internal adiposity in neonates from the GUSTO study [17] but also with higher risk of gestational diabetes mellitus in pregnant women [18]. Furthermore, in the generation R study, higher protein intake during pregnancy was associated with a higher fat-free mass in children at the age of 6 years, but not with their fat mass [19]. Maternal intake of saturated fat or sugar has been related to body fat mass at 5 years [13]. Moreover, low maternal plasma n-3 and high n-6 polyunsaturated fatty acid concentrations during pregnancy were also associated to higher obesity risk or body fat in children [20]. These results may suggest the convenience to assure adequate intakes of macronutrients and specifically polyunsaturated fatty acids during pregnancy.

Mediterranean diet (MedDiet) is a dietary pattern characterized by a high consumption of fruits and vegetables and hence seems appropriate to achieve the extra amounts of vitamins and minerals required because of gestation. Some studies evaluated the effect of MedDiet during pregnancy on different outcomes (Table 1) [1944]. Some of them indicate that higher adherence to the MedDiet pattern during pregnancy may be protective for the development of obesity and adiposity in early childhood, while others do not show significant effects (Table 1). In addition, MedDiet pattern was positively associated with lipoprotein and homocysteine concentrations
[41], and insulin resistance in newborns [42], and negatively associated with gestational diabetes incidence [27] (Table 1). The induction of epigenetic modifications represents a possible explanation for these findings [43], since various micronutrients may influence pregnancy outcomes by altering both maternal and fetal metabolism due to their roles in modulating oxidative stress, enzyme function, signal transduction, and transcription pathways that occur early in pregnancy [43]. These dietary recommendations should be taken into account when implementing nutritional intervention programs, in order to prevent nutritional deficiencies that might adversely impact the health of the mother and the newborn [45].

Indeed, more intervention studies evaluating groups according selected levels of adherence to MedDiet pattern are needed to establish further conclusion and recommendations for pregnant women, since the results of associations in cohort studies are promising. In addition, a new index of MedDiet pattern adapted during pregnancy could be of major interest, since a-priori scores are attributed for components already not consumed by pregnant females, such as alcohol, or recommended for daily or weekly consumptions, such as whole dairy products and fish, respectively.

\section{New Evidence on Metabolic and Molecular Pathways}

Epigenetic control is essential for embryonic and early postnatal development, and its deregulation plays a role in the etiology of several developmental syndromes [46]. Evidence suggests that early life exposure to suboptimal nutrition during pregnancy can affect transcriptional regulation through epigenetic alterations, in adipose tissue, brain, liver, and pancreas [47], contributing to the long-lasting consequences on offspring health. 
High protein intake induced changes in infant metabolome, increasing plasma concentrations of the branched-chain amino acids and consequently insulin levels. These changes seem to inhibit fat oxidation and thereby enhance body fat deposition and the risk of adiposity [48].

Dietary-induced gut microbiota modification may modulate epigenetic gene-expression of adiponectin and resistin through its metabolites such as folate, biotin, and short-chain fatty acids (SCFAs) [49]. In fact, antibiotics modify gut microbiota and increase transcription of the adiponectin and resistin genes in mice fed a high-fat diet by modifying promoter DNA methylation, thus leading to increased fatty acid oxidation and less body weight gain [50]. Therefore, more studies are needed to understand the molecular epigenetic and metabolomic mechanisms involved in the obesity risk associated to early nutrition, in order to achieve improved personalized advices.

\section{Postnatal Determinants of Excess Adiposity}

\section{Infant Feeding}

Considering nutrition during the early postnatal period, breastfeeding is considered by pediatric organizations as the ideal nourishment for infants during their first year of life [51]. In 2014, a systematic review concluded that there is still a controversy in respect to overweight-obesity prevention and breastfeeding, as there are a large number of aspects that may confound this association [52]. In 2017, a randomized controlled trial including 17,046 breastfeeding mother-infant pairs concluded that breastfeeding does not prevent obesity neither in childhood nor in adolescence [53]. However, this study had a number of limitations (such as the observed higher rates of breastfeeding duration in the control group) that make its conclusion not generalizable [52] Besides, a longitudinal study in USA in 2017 including 1,234 children, concluded that breastfeeding at month 1 was associated with a $36 \%$ lower risk for childhood obesity from 24 months and that the longer duration of breastfeeding was correlated with a lower prevalence of childhood obesity [54]. This study has as limitations that data were collected decades ago and might be slightly biased while as strength it includes a number of socioeconomic status variables. In fact, the compendium of social and economic characteristics of children's environment affecting at individual, household, community, or society levels may affect more negatively individuals' health, in- cluding body composition as early as in the gestational period [55]. Indeed, early life risk factors of later excessive weight gain, such as parental smoking and excessive maternal weight gain during pregnancy, gestational diabetes, prematurity, high and low birthweight, caesarean section or not being breastfed are normally grouped in determined socioeconomic patterns [56]. Consequently, children from families in a vulnerable social position are prone to accumulate several risk factors predisposing to lower health future status including inadequate body composition.

Around the sixth month of life, and not early than fourth months, complementary food and beverages (CFBs) introduction should start [57]. This period continues up to 2 years of child age when it is considered that the transition to family feeding habits is finished. In relation to the importance of the introduction timing for later body composition, the literature is not overwhelming. A recent position paper [58] concluded that the introduction of CFBs between the ages of 4 and 5 months compared with the introduction at 6 months is not associated with a different body composition in healthy full-term infants. Little evidence suggests higher odds of overweight/obesity when the introduction of CFBs took place before 4 months, and insufficient evidence exists regarding introduction at age $\geq 7$ months. Therefore, large observational cohorts from both would be highly recommended to clarify these questions [59].

In relation to CFBs, energy is the most determining factor for fat deposition, so it must be adequate for infant requirements [60]. It is important to assure the amount of proteins do not exceed the current recommendations because it may induce metabolic programming of both rapid weight gain (RWG) and increased obesity risk later (Early Protein Hypothesis) [60].

Besides, it seems the perinatal period is relevant in terms of food preference choices development which may also contribute to excess fat deposition later during childhood. In this respect, the role of parental (or caregivers) feeding practices, as well as the early and continuous exposition to all (but especially) healthy foods, continue inspiring research through familiarization via taste lessons, cooking, or playing activities on acceptance [61].

\section{Early Infant Growth}

When consider elevated BMI as risk factor for cardiovascular diseases, for example, it seems that individuals experience only small changes in BMI classification trajectories throughout their life [62]. In a representative sample of Norwegian adolescents from the Medical Birth 
Registry of Norway, longitudinal data showed that associations between birth weight and overweight/obesity were modest at 15-20 years of age, whereas the influence of BMI at 2-4 and 5-7 years on overweight/obesity at 1520 years was moderate to strong [63].

In addition, RWG, during the first months of life, has been also recognized as an important determinant of childhood obesity [64]. A recent nationally representative study in Taiwan [65] found that the association between RWG and the risk of subsequent overweight or obesity was independent of the specific time interval during which RWG occurred before the age of 2 . In a representative cohort of Spanish children followed since birth [66], BMI for age z-score and weight for age z-score trajectories were significantly higher in rapid weight gainers during the first semester of life than their counterparts. These associations were independent of the type of feeding.

\section{Influence of Early Nutrition on Microbiota and Later Obesity Risk}

The microbiota consists of a wide variety of microorganism that colonizes all the compartments of the body. The imbalance of microbiota composition is known as dysbiosis, and it is strongly associated with early nutrition, impacting on the individual's later health and the risk of noncommunicable [67] and metabolic diseases such as obesity [68]. The gut microbiota potentially plays a role in dietary energy harvest and energy storage in the host. Indeed, it is considered a novel factor involved in body weight management, and a contribution of the intestinal microbiota in the onset of obesity has been suggested [69].

Preclinical evidence has suggested that gut microbiota immaturity may lead to childhood undernutrition and growth failure [70]. On the other side, gut microbiota has been implicated in the origin of obesity, since in children with obesity have different microbiota than normal weight children, and the microbial intercorrelation network was also altered [71]. Furthermore, some gut bacterial derived metabolites as the SCFAs found in fecal samples are also more abundant in children with obesity suggesting a higher substrate utilization and energy production from the intestinal microbiota. This confirms that gut microbiota may be important for energy metabolism during obesity development [72]. Indeed, the wellknown relation between microbiota-derived SCFAs, inflammation, and obesity might explain the molecular mechanisms implicated in $[73,74]$, since SCFAs are key molecules able to increased the host capacity to harvest excess energy from the diet, exerting metabolic effects on the via multiple complementary pathways [75]. It has been demonstrated that the most important determinants of the gut microbiota composition in infants are the mode of delivery, gestational age, infant hospitalization, antibiotic administration, and also the type of infant feeding $[67,76]$. In fact, there is a clear clustering of components of newborn-infant microbiota that depends on the type of feeding (human milk versus formula milk) [77]. Breastfeeding is a key factor in the healthy metabolic, immunological, and microbiological programming of the infant's health that is driven by the interaction between milk components and also the mother microbiota [67]. Observational studies have shown that the composition of human milk has an important influence on subsequent infant growth and body composition [72]. Therefore, more studies are needed to find out if there is a link between the type of feeding, the microbiome, and later obesity.

Within food components that may affect these mechanisms, human milk oligosaccharides (HMO) may influence the newborn development and infant growth [78, 79], and the majority of ingested HMO are energetic substrates for specific gut bacteria $[78,79,80]$ which might also influence the microbiome profile. Within HMO, lacto-N-tetraose has been linked to growth, and its presence in human milk is associated with increased fat mass percentage at 5 months of age [81]. Furthermore, the higher risk of obesity in infants with overweight and excessive weight gain mothers may also be influenced by the interaction between breast milk cytokines and microbiota [82].

Later on, solid food greatly influences the microbial ecology after weaning. The influence of dietary composition on children microbiota has been described [83]. The Western diet rich in fat and energy is associated with dysbiosis [84], and specific gut microbiota profiles facilitate the extraction of calories from the diet and their storage in the host adipose tissue [85]. Hence, early dietary manipulation represents a strategy to promote a beneficial gut microbiota and to improve health and weight control [86].

Therefore, knowledge of how early nutrition influence on gut microbiota will help in the design of new nutritional strategies to prevent the development of obesity. These new strategies could be based on the development of new formula milk or solid-food enrich with probiotics or prebiotics that can modulate gut microbiota ecology. 


\section{Conclusions}

Perinatal period represents in many aspects a good opportunity to increase the awareness of families and to apply the adequate health policies to prevent later obesity. The impact of the first 1,000 days of life for programming later obesity risk can be explained by a number of metabolic, epigenetic and metagenomics mechanisms that have been recently explored. From a clinical point of view, factors such as maternal pregestational BMI, should be monitored for instance by controlling glycemic index of their diets or try to better adhere to the Mediterranean diet, although results on reducing infant adiposity are not yet confirmatory. Also, breastfeeding at least during the first semester of life and even better after first year together with the delay in the introduction of complementary feeding until after the fourth month at least, must be recommended from primary care with special emphasis in social vulnerable families.

\section{Conflict of Interest Statement}

The authors have no conflicts of interest to declare.

\section{Funding Sources}

This research was funded by the PN I+D+I 2008-2011 (Spain), ISCIII- Sub-Directorate General for Research Assessment and Promotion and the European Regional Development Fund (ERDF), and RETICS Maternal and Child Health and Development Network, SAMID Network, Ref. RD16/0022.

\section{Author Contributions}

All authors have designed, wrote, and reviewed the final content of this manuscript.

\section{References}

1 Thaker VV. Genetic and epigenetic causes of obesity. Adolesc Med State Art Rev. 2017; 28(2):379-405.

2 Schwarzenberg SJ, Georgieff MK; Committee on Nutrition. Advocacy for improving nutrition in the first 1000 days to support childhood development and adult health. Pediatrics. 2018;141(2):e20173716.

3 Smith J, Cianflone K, Biron S, Hould FS, Lebel S, Marceau S, et al. Effects of maternal surgical weight loss in mothers on intergenerational transmission of obesity. J Clin Endocrinol Metab. 2009 Nov;94(11):4275-83.

4 Larqué E, Labayen I, Flodmark CE, Lissau I, Czernin S, Moreno LA, et al. From conception to infancy: early risk factors for childhood obesity. Nat Rev Endocrinol. 2019;15: 456-78.

5 Voerman E, Santos S, Patro Golab B, Amiano P, Ballester F, Barros H, et al. Maternal body mass index, gestational weight gain, and the risk of overweight and obesity across childhood: an individual participant data metaanalysis. PLoS Med. 2019 Feb 11;16(2): e1002744.

6 Fernandez-Twinn DS, Hjort L, Novakovic B, Ozanne SE, Saffery R. Intrauterine programming of obesity and type 2 diabetes. Diabetologia. 2019 Oct;62(10):1789-801.

7 Linabery AM, Nahhas RW, Johnson W, Choh AC, Towne B, Odegaard AO, et al. Stronger influence of maternal than paternal obesity on infant and early childhood body mass index: the Fels Longitudinal Study. Pediatr Obes. 2013 Jun;8(3):159-69.

A Review on Early Predictors of Excess Adiposity in Childhood
8 International Weight Management in Pregnancy (i-WIP) Collaborative Group. Effect of diet and physical activity based interventions in pregnancy on gestational weight gain and pregnancy outcomes: meta-analysis of individual participant data from randomised trials. BMJ. 2017 Jul 19;358:j3119.

9 Poston L, Bell R, Croker H, Flynn AC, Godfrey KM, Goff L, et al. Effect of a behavioural intervention in obese pregnant women (the UPBEAT study): a multicentre, randomised controlled trial. Lancet Diabetes Endocrinol. 2015;3:767-77.

10 Koletzko B, Brands B, Poston L, Godfrey K, Demmelmair H; Early Nutrition Project. Early nutrition programming of long-term health. Proc Nutr Soc. 2012 Aug;71(3):371-8.

11 World Health Organization. WHO recommendations on antenatal care for a positive pregnancy experience. Geneva: WHO Library; 2016

12 Moses RG, Luebcke M, Davis WS, Coleman KC, Tapsell LC, Petocz P, et al. Effect of a lowglycemic-index diet during pregnancy on obstetric outcomes. Am J Clin Nutr. 2006;84: 807-12.

13 Murrin C, Shrivastava A, Kelleher CC. Maternal macronutrient intake during pregnancy and 5 years postpartum and associations with child weight status aged five. Eur J Clin Nutr. 2013;67:670-9.

14 Patel N, Godfrey KM, Pasupathy D, Levin J, Flynn AC, Hayes L, et al. Infant adiposity following a randomised controlled trial of a behavioural intervention in obese pregnancy. Int J Obes. 2017;41(7):1018-26.
15 Dodd JM, Deussen AR, Louise J. Effects of an antenatal dietary intervention in women with obesity or overweight on child outcomes at 3-5 years of age: LIMIT randomised trial follow-up. Int J Obes. 2020 Jul;44(7):1531-5.

16 Chen LW, Aris IM, Bernard JY, Tint MT, Colega $\mathrm{M}$, Gluckman PD, et al. Associations of maternal macronutrient intake during pregnancy with infant BMI peak characteristics and childhood BMI. Am J Clin Nutr. 2017 Mar;105(3):705-13.

17 Chen LW, Tint MT, Fortier MV, Aris IM, Bernard JY, Colega M, et al. Maternal macronutrient intake during pregnancy is associated with neonatal abdominal adiposity: the Growing Up in Singapore Towards healthy Outcomes (GUSTO) Study. J Nutr. 2016 Aug; 146(8):1571-9.

18 Pang WW, Colega M, Cai S, Chan YH, Padmapriya N, Chen LW, et al. Higher maternal dietary protein intake is associated with a higher risk of gestational diabetes mellitus in a Multiethnic Asian Cohort. J Nutr. 2017 Apr; 147(4):653-60.

19 Timmermans S, Steegers-Theunissen RP, Vujkovic M, den Breeijen H, Russcher H, Lindemans J, et al. The Mediterranean diet and fetal size parameters: the Generation R Study. Br J Nutr. 2012 Oct 28;108(8):1399-409.

20 Vidakovic AJ, Gishti O, Voortman T, Felix JF, Williams MA, Hofman A, et al. Maternal plasma PUFA concentrations during pregnancy and childhood adiposity: the Generation $\mathrm{R}$ Study. Am J Clin Nutr. 2016 Apr;103(4): 1017-25. 
21 Chatzi L, Mendez M, Garcia R, Roumeliotaki T, Ibarluzea J, Tardón A, et al. INMA and RHEA study groups. Mediterranean diet adherence during pregnancy and fetal growth: INMA (Spain) and RHEA (Greece) motherchild cohort studies. Br J Nutr. 2012 Jan; 107(1):135-45.

22 Chatzi L, Rifas-Shiman SL, Georgiou V, Joung KE, Koinaki S, Chalkiadaki G, et al. Adherence to the mediterranean diet during pregnancy and offspring adiposity and cardiometabolic traits in childhood. Pediatr Obes. 2017 Aug;12 Suppl 1(Suppl 1):47-56.

23 Smith LK, Draper ES, Evans TA, Field DJ, Johnson SJ, Manktelow BN, et al. Associations between late and moderately preterm birth and smoking, alcohol, drug use and diet: a population-based case-cohort study. Arch Dis Child Fetal Neonatal Ed. 2015 Nov; 100(6):F486-91.

24 Monteagudo C, Mariscal-Arcas M, HerasGonzalez L, Ibañez-Peinado D, Rivas A, OleaSerrano F. Effects of maternal diet and environmental exposure to organochlorine pesticides on newborn weight in Southern Spain. Chemosphere. 2016 Aug;156:135-42.

25 Parlapani E, Agakidis C, Karagiozoglou-Lampoudi T, Sarafidis K, Agakidou E, Athanasiadis A, et al. The mediterranean diet adherence by pregnant women delivering prematurely: association with size at birth and complications of prematurity. J Matern Fetal Neonatal Med. 2019 Apr;32(7):1084-91.

26 Gómez Roig MD, Mazarico E, Ferrero S, Montejo R, Ibáñez L, Grima F, et al. Differences in dietary and lifestyle habits between pregnant women with small fetuses and appropriate-for-gestational-age fetuses. J Obstet Gynaecol Res. 2017 Jul;43(7):1145-51.

27 Assaf-Balut C, García de la Torre N, Durán A, Fuentes M, Bordiú E, Del Valle L, et al. A Mediterranean diet with additional extra virgin olive oil and pistachios reduces the incidence of gestational diabetes mellitus (GDM): a randomized controlled trial: the St. Carlos GDM prevention study. PLoS One. 2017 Oct 19;12(10):e0185873.

28 Martínez-Galiano JM, Amezcua-Prieto C, Salcedo-Bellido I, González-Mata G, Bueno-Cavanillas A, Delgado-Rodríguez M. Maternal dietary consumption of legumes, vegetables and fruit during pregnancy, does it protect against small for gestational age? BMC Pregnancy Childbirth. 2018 Dec 11;18(1):486.

29 Peraita-Costa I, Llopis-González A, PeralesMarín A, Sanz F, Llopis-Morales A, MoralesSuárez-Varela M. A retrospective cross-sectional population-based study on prenatal levels of adherence to the mediterranean diet: maternal profile and effects on the newborn. Int J Environ Res Public Health. 2018 Jul 19; 15(7): 1530.

30 Fernandez-Barres S, Romaguera D, Valvi D, Martinez D, Vioque J, Navarrete-Munoz EM, et al. Mediterranean dietary pattern in pregnant women and offspring risk of overweight and abdominal obesity in early childhood: the
INMA birth cohort study. Pediatr Obes. 2016; 11:491-9.

31 Saunders L, Guldner L, Costet N, Kadhel P, Rouget F, Monfort C, et al. Effect of a Mediterranean diet during pregnancy on fetal growth and preterm delivery: results from a French Caribbean Mother-Child Cohort Study (TIMOUN). Paediatr Perinat Epidemiol. 2014;28:235-44.

32 Fernandez-Barres S, Romaguera D, Valvi D, Martinez D, Vioque J, Navarrete-Munoz EM, et al. Mediterranean dietary pattern in pregnant women and offspring risk of overweight and abdominal obesity in early childhood: the INMA birth cohort study. Pediatr Obes. 2016;11:491-9.

33 Castro-Rodriguez JA, Ramirez-Hernandez M, Padilla O, Pacheco-Gonzalez RM, PérezFernández V, Garcia-Marcos L. Effect of foods and mediterranean diet during pregnancy and first years of life on wheezing, rhinitis and dermatitis in preschoolers. Allergol Immunopathol. 2016;44:400-9.

34 Tomaino L, Reyes Suárez D, Reyes Domínguez A, García Cruz LM, Ramos Díaz M, Serra Majem L. Adherence to mediterranean diet is not associated with birthweight: results form a sample of Canarian pregnant women. Nutr Hosp. 2020 Feb 17;37(1):86-92.

35 Peraita-Costa I, Llopis-González A, PeralesMarín A, Diago V, Soriano JM, Llopis-Morales A, et al. Maternal profile according to mediterranean diet adherence and small for gestational age and preterm newborn outcomes. Public Health Nutr. 2020 Apr 29;24:1372-84.

36 Assaf-Balut C, García de la Torre N, Fuentes M, Durán A, Bordiú E, Del Valle L, et al. A high adherence to six food targets of the mediterranean diet in the late first trimester is associated with a reduction in the risk of materno-foetal outcomes: the St. Carlos Gestational Diabetes Mellitus Prevention Study. Nutrients. 2018 Dec 31;11(1):66.

37 H Al Wattar B, Dodds J, Placzek A, Beresford L, Spyreli E, Moore A, et al. Mediterraneanstyle diet in pregnant women with metabolic risk factors (ESTEEM): a pragmatic multicentre randomised trial. PLoS Med. 2019 Jul 23; 16(7):e1002857.

38 Olmedo-Requena R, Gómez-Fernández J, Amezcua-Prieto C, Mozas-Moreno J, Khan KS, Jiménez-Moleón JJ. Pre-pregnancy adherence to the mediterranean diet and gestational diabetes mellitus: a case-control study. Nutrients. 2019 May 1;11(5):1003.

39 García de la Torre N, Assaf-Balut C, Jiménez Varas I, Del Valle L, Durán A, Fuentes M, et al. Effectiveness of following mediterranean diet recommendations in the real world in the incidence of gestational diabetes mellitus ( $\mathrm{gdm})$ and adverse maternal-foetal outcomes: a prospective, universal, interventional study with a single group. the St. Carlos Study. Nutrients. 2019 May 28;11(6):1210.

40 Melero V, Assaf-Balut C, Torre NG, Jiménez I, Bordiú E, Valle LD, et al. Benefits of adhering to a mediterranean diet supplemented with extra virgin olive oil and pistachios in pregnancy on the health of offspring at 2 years of age. Results of the San Carlos Gestational Diabetes Mellitus Prevention Study. J Clin Med. 2020 May 13;9(5):1454.

41 Gesteiro E, Rodríguez Bernal B, Bastida S, Sánchez-Muniz FJ. Maternal diets with low healthy eating index or mediterranean diet adherence scores are associated with high cord-blood insulin levels and insulin resistance markers at birth. Eur J Clin Nutr. 2012; 66:1008-15.

42 Gesteiro E, Bastida S, Rodríguez Bernal B, Sánchez-Muniz FJ. Adherence to Mediterranean diet during pregnancy and serum lipid, lipoprotein and homocysteine concentrations at birth. Eur J Nutr. 2015;54:1191-9.

43 Gonzalez-Nahm S, Mendez M, Robinson W, Murphy SK, Hoyo C, Hogan V, et al. Low maternal adherence to a mediterranean diet is associated with increase in methylation at the MEG3-IG differentially methylated region in female infants. Environ Epigenet. 2017 May 6; 3(2): $\operatorname{dvx} 007$

44 Mantzoros CS, Sweeney L, Williams CJ, Oken E, Kelesidis T, Rifas-Shiman SL, et al. Maternal diet and cord blood leptin and adiponectin concentrations at birth. Clin Nutr. 2010; 29:622-6.

45 Jardí C, Aparicio E, Bedmar C, Aranda N, Abajo S, March G, et al. Food Consumption during pregnancy and post-partum. ECLIPSES Study. Nutrients. 2019 Oct 14;11(10):2447.

46 Lukaszewski MA, Eberlé D, Vieau D, Breton C. Nutritional manipulations in the perinatal period program adipose tissue in offspring. Am J Physiol Endocrinol Metab. 2013; 305(10):E1195-207.

47 Lee HS. Impact of maternal diet on the epigenome during in utero life and the developmental programming of diseases in childhood and adulthood. Nutrients. 2015;7:9492-507.

48 Haschke F. Summary: early nutrition and obesity prevention. Nestle Nutr Inst Workshop Ser. 2016;85:111-2.

49 Remely M, Haslberger AG. The microbial epigenome in metabolic syndrome. Mol Aspects Med. 2017;54:71-7.

50 Yao H, Fan C, Lu Y, Fan X, Xia L, Li P, et al. Alteration of gut microbiota affects expression of adiponectin and resistin through modifying DNA methylation in high-fat diet-induced obese mice. Genes Nutr. 2020; 26;15(1):12.

51 World Health Organization. Breasfeeding recommendations. Available from: https:// www.who.int/health-topics/breastfeeding\# tab=tab_2 Accessed 2021 April 6.

52 Lefebvre CM, John RM. The effect of breastfeeding on childhood overweight and obesity: a systematic review of the literature. J Am Assoc Nurse Pract. 2014;26(7):386-401.

53 Martin RM, Kramer MS, Patel R, Rifas-Shiman SL, Thompson J, Yang S, et al. Effects of promoting long-term, exclusive breastfeeding on adolescent adiposity, blood pressure, and growth trajectories: a secondary analysis of a randomized clinical trial. JAMA Pediatr. 2017 Jul 3;171(7):e170698. 
54 Wang L, Collins C, Ratliff M, Xie B, Wang Y. Breastfeeding reduces childhood obesity risks. Child Obes. 2017 Jun;13(3):197-204.

55 Iguacel I, Gasch-Gallén Á, Ayala-Marín AM, De Miguel-Etayo P, Moreno LA. Social vulnerabilities as risk factor of childhood obesity development and their role in prevention programs. Int J Obes. 2021 Jan;45(1):1-11.

56 Bammann K, Peplies J, De Henauw S, Hunsberger M, Molnar D, Moreno LA, et al. Early life course risk factors for childhood obesity: the IDEFICS case-control study. PLoS One. 2014;9(2):e86914

57 English LK, Obbagy JE, Wong YP, Butte NF, Dewey KG, Fox MK, et al. Timing of introduction of complementary foods and beverages and growth, size, and body composition: a systematic review. Am J Clin Nutr. 2019; 109(Suppl_7):935S-55S.

58 Fewtrell M, Bronsky J, Campoy C, Domellöf M, Embleton N, Fidler Mis N, et al. Complementary feeding: a position paper by the european society for paediatric gastroenterology, hepatology, and nutrition (espghan) committee on nutrition. J Pediatr Gastroenterol Nutr. 2017 Jan;64(1):119-32.

59 D’Auria E, Borsani B, Pendezza E, Bosetti A, Paradiso L, Zuccotti GV, et al. Complementary feeding: pitfalls for health outcomes. Int J Environ Res Public Health. 2020;17(21): 7931.

60 Koletzko B, Demmelmair H, Grote V, Prell C, Weber M. High protein intake in young children and increased weight gain and obesity risk. Am J Clin Nutr. 2016;103(2):303-4.

61 Nicklaus S, Schwartz C. Early influencing factors on the development of sensory and food preferences. Curr Opin Clin Nutr Metab Care. 2019;22(3):230-5.

62 Singh AS, Mulder C, Twisk JW, van Mechelen W, Chinapaw MJ. Tracking of childhood overweight into adulthood: a systematic review of the literature. Obes Rev. 2008;9(5): 474-88.

63 Evensen E, Emaus N, Kokkvoll A, Wilsgaard T, Furberg AS, Skeie G. The relation between birthweight, childhood body mass index, and overweight and obesity in late adolescence: a longitudinal cohort study from Norway, The Tromsø Study, Fit Futures. BMJ Open. 2017; 7(6):e015576.
64 Zheng M, Lamb KE, Grimes C, Laws R, Bolton K, Ong KK, et al. Rapid weight gain during infancy and subsequent adiposity: a systematic review and meta-analysis of evidence. Obes Rev. 2018;19(3):321-32.

65 Li YF, Lin SJ, Chiang TL. Timing of rapid weight gain and its effect on subsequent overweight or obesity in childhood: findings from a longitudinal birth cohort study. BMC Pediatr. 2020;20(1):293.

66 Flores-Barrantes P, Iguacel I, Iglesia-Altaba I, Moreno LA, Rodríguez G. Rapid weight gain, infant feeding practices, and subsequent body mass index trajectories: the CALINA Study. Nutrients. 2020;12(10):3178.

67 Isolauri E, Rautava S, Salminen S, Collado MC. Early-life nutrition and microbiome development. Nestle Nutr Inst Workshop Ser. 2019;90:151-62.

68 Duca F, Gérard P, Covasa M, Lepage P. Metabolic interplay between gut bacteria and their host. Front Horm Res. 2014;42:73-82.

69 Harris K, Kassis A, Major G, Chou CJ. Is the gut microbiota a new factor contributing to obesity and its metabolic disorders? J Obes. 2012;2012:879151.

70 Blanton LV, Charbonneau MR, Salih T, Barratt MJ, Venkatesh S, Ilkaveya O, et al. Gut bacteria that prevent growth impairments transmitted by microbiota from malnourished children. Science. 2016;351(6275).

71 Riva A, Borgo F, Lassandro C, Verduci E, Morace G, Borghi E, et al. Pediatric obesity is associated with an altered gut microbiota and discordant shifts in Firmicutes populations. Environ Microbiol. 2017;19:95-105.

72 Eriksen KG, Christensen SH, Lind MV, Michaelsen KF. Human milk composition and infant growth. Curr Opin Clin Nutr Metab Care. 2018;21(3):200-6.

73 Liu B-N, Liu X-T, Liang Z-H, Wang J-H. Gut microbiota in obesity. Wjg. 2021;727(25): 3837-50.

74 Qu H, Song L, Zhang Y, Gao ZY, Shi DZ. The effect of prebiotic products on decreasing adiposity parameters in overweight and obese individuals: a systematic review and metaanalysis. Curr Med Chem. 2021;28(2):41931.

75 Barrea L, Muscogiuri G, Annunziata G, Laudisio D, Pugliese G, Salzano C, et al. From gut microbiota dysfunction to obesity: could short-chain fatty acids stop this dangerous course? Hormones. 2019;18(3):245-50.
76 Mesa MD, Loureiro B, Iglesia I, Fernandez Gonzalez S, Llurba Olivé E, García Algar O, et al. The evolving microbiome from pregnancy to early infancy: a comprehensive review. Nutrients. 2020;12(1):133.

77 Gomez-Llorente C, Plaza-Diaz J, Aguilera M, Muñoz-Quezada S, Bermudez-Brito M, PesoEcharri P, et al. Three main factors define changes in fecal microbiota associated with feeding modality in infants. J Pediatr Gastroenterol Nutr. 2013;57(4):461-6.

78 Collado MC, Laitinen K, Salminen S, Isolauri E. Maternal weight and excessive weight gain during pregnancy modify the immunomodulatory potential of breast milk. Pediatr Res. 2012;72:77-85

79 Isolauri E, Rautava S, Salminen S, Collado MC. Early-life nutrition and microbiome development. Nestle Nutr Inst Workshop Ser. 2019;90:151-62.

80 Vandenplas Y, Carnielli VP, Ksiazyk J, Luna MS, Migacheva N, Mosselmans JM, et al. Factors affecting early-life intestinal microbiota development. Nutrition. 2020;78:110812.

81 Alderete TL, Autran C, Brekke BE, Knight R, Bode L, Goran MI, et al. Associations between human milk oligosaccharides and infant body composition in the first 6 mo of life. Am J Clin Nutr. 2015;102:1381-8.

82 Elison E, Vigsnaes LK, Rindom Krogsgaard L, Rasmussen J, Sørensen N, McConnell B, et al. Oral supplementation of healthy adults with $2^{\prime}$-O-fucosyllactose and lacto-N-neotetraose is well tolerated and shifts the intestinal microbiota. Br J Nutr. 2016;116:1356-68.

83 Deering KE, Devine A, O’Sullivan TA, Lo J, Boyce MC, Christophersen CT. Characterizing the composition of the pediatric gut microbiome: a systematic review. Nutrients. 2019; 19;12(1):16.

84 Hold GL. Western lifestyle: a "master" manipulator of the intestinal microbiota? Gut. 2014;63:5-6

85 Bäckhed F, Ding H, Wang T, Hooper LV, Koh GY, Nagy A, et al. The gut microbiota as an environmental factor that regulates fat storage. Proc Natl Acad Sci U S A. 2004 Nov 2; 101(44):15718-23

86 Iozzo P, Sanguinetti E. Early dietary patterns and microbiota development: still a way to go from descriptive interactions to health-relevant solutions. Front Nutr. 2018 Feb 2;5:5. 